\title{
ANALYSIS OF PATIENT AND PHYSICIAN DISCREPANCY IN GLOBAL ASSESSMENT OF SYSTEMIC AUTOIMMUNE MYOPATHY DISEASE ACTIVITY
}

\author{
Rafael Alves Cordeiro ${ }^{1, \star}$, Frida Marina Fischer ${ }^{1}$, Samuel Katsuyuki Shinjo ${ }^{1}$ \\ 1.Universidade de São Paulo, São Paulo (SP), Brazil. \\ *Corresponding author: rafael19abc@hotmail.com
}

\section{BACKGROUND}

Global disease activity scores assessed through visual analog scales (VAS) capture patient and physician impressions of disease activity (DA). This study investigated the concordance and the discordance in the perception of DA between patients with systemic autoimmune myopathies (SAMs) and their physicians. Possible sources of discrepancy were analyzed.

\section{METHODS}

Patients with SAMs (EULAR/ACR 2017 classification criteria) were included from the outpatient clinic of a tertiary hospital in São Paulo, Brazil. They rated their level of global DA on a VAS (0-10 cm). Physician global assessment of DA was blinded performed to the patient evaluation. A discrepancy score was calculated by subtracting physician global assessment from patient global assessment. Based on this score, three groups of patients were defined: (I) no discrepancy when the difference was within the range of -2.0 to +2.0 ; (II) negative discrepancy when the difference was $<-2.0$ (patient global assessment of DA underrated in relation to physician's evaluation); (III) positive discrepancy when the difference was $>+2.0$ (patient global assessment of DA overrated in relation to physician's evaluation). Logistic regression model was used to identify predictors of discordance at a significance level of 0.05 .

\section{RESULTS}

Seventy-five patients with SAMs participated in the study ( $66.7 \%$ female) with mean age of $44.1 \pm 9.4$ years and mean disease duration of $6.2 \pm 4.5$ years. Discordance was found in $28 \%(n=21)$ of patient and physician global VAS for DA. Negative discrepancy was found in $3(4 \%)$, positive discrepancy in $18(24 \%)$, and no discrepancy in $54(72 \%)$ assessments. Due to the small number, negative discrepancy cases were excluded from the analysis. Positive discrepancy was associated with: older age $(p=0.012)$, personal history of depression ( $p=0.009)$, past joint involvement $(p=0.025)$, higher MMT-8 score $(p=0.035)$ and lower VAS score for extramuscular DA ( $p=0.033$ ). In the binary logistic regression model, for each additional year of age, the chance of positive discrepancy on global DA increases, on average, by $9 \%(\mathrm{OR}=1.09 ; 95 \% \mathrm{Cl}=1.01-1.17, \mathrm{p}=0.034)$. Personal history of depression increases the chance of positive discrepancy by $829 \%(\mathrm{OR}=9.29 ; 95 \% \mathrm{Cl}=1.52-56.89, \mathrm{p}=0.016)$.

\section{CONCLUSION}

Almost 30\% of patients had discordance in DA assessment from their physicians. The majority of them overrated their DA in relation to physician's evaluation. These patients tend to be older and are more likely to have personal history of depression and joint involvement, and to have milder disease according to the medical assessment (higher MMT-8 score and lower VAS score for extramuscular DA).

\section{KEYWORDS}

Dermatomyositis, Polymyositis, Self-assessment, Visual analogue scale, Patient reported outcome measures. 